Case Reports
in Dermatology
Case Rep Dermatol 2021;13:47-53

DOI: $10.1159 / 000511369$

Published online: January 28, 2021
(C) 2021 The Author(s)

Published by S. Karger AG, Basel www.karger.com/cde

This article is licensed under the Creative Commons Attribution-NonCommercial 4.0 International License (CC BY-NC) (http://www.karger.com/Services/OpenAccessLicense). Usage and distribution for commercial purposes requires written permission.

\title{
Acute Generalized Exanthematous Pustulosis with Multiple Organ Failure
}

\author{
Tausif Syed $^{\mathrm{a}} \quad$ Abdullah Sayied Abdullah $^{\mathrm{a}} \quad$ Mahmood Mubasher $^{\mathrm{a}}$ \\ Zohaib Yousaf $^{b} \quad$ Mouhand F.H. Mohamed ${ }^{b}$ Richard Alweis ${ }^{a}$ \\ alnternal Medicine Rochester Regional Health, Rochester, NY, USA; bInternal Medicine, \\ Hamad Medical Corporation, Doha, Qatar
}

\section{Keywords}

Acute generalized exanthematous pustulosis · Shock · Ceftriaxone

\section{Abstract}

Acute generalized exanthematous pustulosis (AGEP) is a rare, self-limiting condition. It presents with sterile skin pustules. We present a middle-aged lady with fluid nonresponsive circulatory shock and multiple organ dysfunction secondary to AGEP.

\author{
(c) 2021 The Author(s) \\ Published by S. Karger AG, Basel
}

\section{Introduction}

Acute generalized exanthematous pustulosis (AGEP) is a rare condition presenting with numerous small, nonfollicular, sterile skin pustules on an erythematous base. It can be accompanied by fever and leukocytosis, but their presence is not mandatory $[1,2]$. These are usually self-limited [3]. We present the rare situation of severe AGEP, initially diagnosed as septic shock, requiring vasopressor support.

\begin{tabular}{ll}
\hline & Zohaib Yousaf \\
Karger $₹$ & Hamad Medical Corporation \\
PO Box 3050 \\
Doha (Qatar) \\
zohaib.yousaf@gmail.com
\end{tabular}




\section{Case Reports in Dermatology}

Case Rep Dermatol 2021;13:47-53

DOI: $10.1159 / 000511369$

(C) 2021 The Author(s). Published by S. Karger AG, Basel www.karger.com/cde

Syed et al.: Acute Severe Generalized Exanthematous Pustulosis

\section{Case Report}

A 50-year-old, morbidly obese female with a past medical history of hypertension, hyperlipidemia, polycystic ovary syndrome, and obstructive sleep apnea on CPAP presented to the emergency department with high-grade fever $\left(39.5^{\circ} \mathrm{C}\right)$, tachycardia $(118 \mathrm{bpm})$, diarrhea, leukocytosis $\left(11,000 / \mathrm{mm}^{3}\right)$ with left shift, acute renal failure, and liver dysfunction (Table 1$)$. She was prescribed amoxicillin at urgent care for suspicion of tick bite 8 days previously as she was allergic to doxycycline. Upon examination, she was found to have confluent erythema described as tiny pustules forming lakes of pus on her chin, cheeks, upper neck, and hairline and just below the ear, as well as diffuse hives on the back and face (Fig. 1, 2). There was no hemorrhagic crusting, and Nikolsky's sign was negative. The mucous membranes were spared. The genital region showed no visible ulcers. Over the next few hours, she experienced fluidnonresponsive hypotension. She needed elective intubation due to increased work of breathing and respiratory fatigue. She also required blood pressure support with norepinephrine. With a working diagnosis of septic shock, she received intravenous fluids and antibiotics, including ceftriaxone, metronidazole, and levofloxacin. She also received intravenous bicarbonate followed by 2 sessions of hemodialysis for her acute renal failure causing severe metabolic acidosis.

As part of sepsis workup, multiple blood cultures turned out negative. Since the pustules were nonfollicular, bacterial folliculitis was less likely. A swab from the affected site showed normal skin commensals. The other principal noninfectious differential diagnoses included toxic epidermal necrosis/Steven-Johnson syndrome, pustular psoriasis, drug rash with eosinophilia and systemic symptoms, bullous impetigo, and other drug eruptions like the one associated with hydroxychloroquine [4]. The EuroSCAR study scoring system showed the diagnosis probably to be AGEP for our patient (Table 2).

Awaiting the results of the workup, the dermatologist indicated a clinical picture consistent with AGEP due to amoxicillin, and possibly potentiated by ceftriaxone. Though AGEP does not typically need systemic steroids, in this case, with liver and kidney dysfunction, the patient received intravenous methylprednisolone (100 mg once daily) for 3 days with discontinuation of antibiotics. Penicillin and cephalosporin were added to the patient's allergy list to prevent recurrence. Over the next 2 days, the patient's condition improved. Her vitals stabilized, she was extubated, and her rash began to clear with desquamation (Fig. 3). On day 9, she was discharged home. She received triamcinolone $0.1 \%$ cream for 2 weeks post-discharge and improved.

\section{Discussion}

AGEP is a rare cutaneous disorder [5]. It is mostly an adverse drug reaction, but other triggers are known. It has a female predominance [6]. AGEP is a type IV hypersensitivity reaction mediated by CD8+/CD4+ T cells. Histopathologically, we find spongiform subcorneal intraepidermal pustules. The clinical manifestation of AGEP consists of pin-sized sterile pustules on an erythematous base that start in the intertriginous areas and spread to the rest of the 


\section{Case Reports in Dermatology}

Case Rep Dermatol 2021;13:47-53

DOI: $10.1159 / 000511369$

(C) 2021 The Author(s). Published by S. Karger AG, Basel www.karger.com/cde

Syed et al.: Acute Severe Generalized Exanthematous Pustulosis

body [2]. There may be a sensation of itching or burning. AGEP is associated with fever and neutrophilic leukocytosis [3, 7]. After discontinuation of the causing drug, the skin lesions begin to resolve within 2 weeks with desquamation. Most of these cases are self-limiting with less than 5\% mortality, but severe life-threatening cases needing ICU care and vasopressor support, as in our case, have been reported [2].

A diagnosis can be made by history-taking and examination in most cases. Usually, a patient presents with a history of taking an offending agent such as penicillin or cephalosporin. Pustules on an erythematous, edematous skin develop in about 5 days from initiation of the offending drug. The AGEP validation score generated by the EuroSCAR study group can be used to help in the diagnosis of AGEP [2]. The AGEP validation scoring system provides the probability of the diagnosis of AGEP. The categories include definite AGEP, probable AGEP, possible AGEP, and doubtful AGEP [8].

Based on this scoring system, the diagnosis in our patient was probable with a score of 6 (Table 2). The other differential diagnoses included septic shock, toxic epidermal necrolysis, Stevens-Johnson syndrome, and pustular psoriasis. Septic shock could be ruled out after a thorough infectious workup and inadequate response to antibiotics in this case. Toxic epidermal necrosis and Steven-Johnson syndrome were less probable as they involve the mucous membranes, unlike AGEP, which rarely involves the mucous membrane (Table 3) [1]. AGEP should also be differentiated from generalized pustular psoriasis. In pustular psoriasis, there is a past history of psoriasis; there might be other psoriatic skin lesions, the onset is slow, and the patient may get recurrent pustular eruptions. Also, beta-lactam antibiotics are a typical trigger of AGEP, in contrast to pustular psoriasis. AGEP is an acute, self-limiting disease. It is not associated with a history of psoriasis. Once the diagnosis of AGEP is established, a skin patch test may aid in determining the causative drug. It may be challenging to diagnose AGEP even with a skin patch test, since the sensitivity of the test is only $58 \%$ [2]. In such cases, a histopathological examination can be helpful.

Treatment is the immediate withdrawal of the offending medications such as beta-lactam antibiotics, macrolide, and cephalosporins [1]. Symptoms such as itching and fever can be controlled with topical steroids. Topical steroids decrease the duration of hospitalization [9]. Emollients may be used during the desquamation phase. If patients have extensive rashes, systemic steroids have been used [10]. Antibiotics are usually not required, but they may be needed in the event that the pustules get infected. This case is unique, as such a severe form of AGEP is extremely rarely encountered.

\section{Conclusions}

AGEP is a rare clinical condition that may be misdiagnosed. Usually, it is self-limiting, and withdrawal of the causative medication is the only treatment required in most of the cases. In severe cases, however, ICU admission, vasopressor support, and steroids may be needed.

\section{Karger'=}




\section{Case Reports in Dermatology}

Case Rep Dermatol 2021;13:47-53

DOI: $10.1159 / 000511369$

(C) 2021 The Author(s). Published by S. Karger AG, Basel www.karger.com/cde

Syed et al.: Acute Severe Generalized Exanthematous Pustulosis

\section{Statement of Ethics}

The patient has given written informed consent to publish this case, including the publication of images. The institute's committee on human research approved the manuscript. We avoided yielding information revealing the subject's identity. The research was conducted ethically in accordance with the World Medical Association Declaration of Helsinki (https://www.wma.net/policies-post/wma-declaration-of-helsinki-ethical-principles-formedical-research-involving-human-subjects/).

\section{Conflict of Interest Statement}

The authors certify that they have no conflict of interest and no affiliations with or involvement in any organization or entity with any financial or nonfinancial interest in the subject matter or materials discussed in this manuscript.

\section{Funding Sources}

No funding was received.

\section{Author Contributions}

T.S.: case identification, manuscript writing, and informed consent. A.S.A., M.M., M.F.H.M., and R.A.: manuscript writing and literature review. Z.Y.: literature review, provided revisions to scientific content of the manuscript, and provided stylistic/grammatical revisions to the manuscript.

\section{References}

1 Sidoroff A. Acute generalized exanthematous pustulosis. Chem Immunol Allergy. 2012;97:139-48.

2 Feldmeyer L, Heidemeyer K, Yawalkar N. Acute Generalized Exanthematous Pustulosis: Pathogenesis, Genetic Background, Clinical Variants and Therapy. Int J Mol Sci. 2016 Jul;17(8):1214.

3 Roujeau JC, Bioulac-Sage P, Bourseau C, Guillaume JC, Bernard P, Lok C, et al. Acute generalized exanthematous pustulosis. Analysis of 63 cases. Arch Dermatol. 1991 Sep;127(9):1333-8.

4 Schwartz RA, Janniger CK. Generalized pustular figurate erythema: a newly delineated severe cutaneous drug reaction linked with hydroxychloroquine. Dermatol Ther (Heidelb). 2020 May;33(3):e13380.

5 De A, Das S, Sarda A, Pal D, Biswas P. Acute generalised exanthematous pustulosis: an update. Indian J Dermatol. 2018 Jan-Feb;63(1):22-9.

6 Sidoroff A, Halevy S, Bavinck JN, Vaillant L, Roujeau JC. Acute generalized exanthematous pustulosis (AGEP) - a clinical reaction pattern. J Cutan Pathol. 2001 Mar;28(3):113-9.

7 Hotz C, Valeyrie-Allanore L, Haddad C, Bouvresse S, Ortonne N, Duong TA, et al. Systemic involvement of acute generalized exanthematous pustulosis: a retrospective study on 58 patients. Br J Dermatol. 2013 Dec;169(6):1223-32. 


\section{Case Reports in Dermatology}

Case Rep Dermatol 2021;13:47-53

(c) 2021 The Author(s). Published by S. Karger AG, Basel www.karger.com/cde

Syed et al.: Acute Severe Generalized Exanthematous Pustulosis

8 Sidoroff A, Dunant A, Viboud C, Halevy S, Bavinck JN, Naldi L, et al. Risk factors for acute generalized exanthematous pustulosis (AGEP) - results of a multinational case-control study (EuroSCAR). Br J Dermatol. 2007 Nov;157(5):989-96.

9 Ingen-Housz-Oro S, Hotz C, Valeyrie-Allanore L, Sbidian E, Hemery F, Chosidow O, et al. Acute generalized exanthematous pustulosis: a retrospective audit of practice between 1994 and 2011 at a single centre. Br J Dermatol. 2015;172(5):1455-7.

10 Szatkowski J, Schwartz RA. Acute generalized exanthematous pustulosis (AGEP): a review and update. J Am Acad Dermatol. 2015 Nov;73(5):843-8.

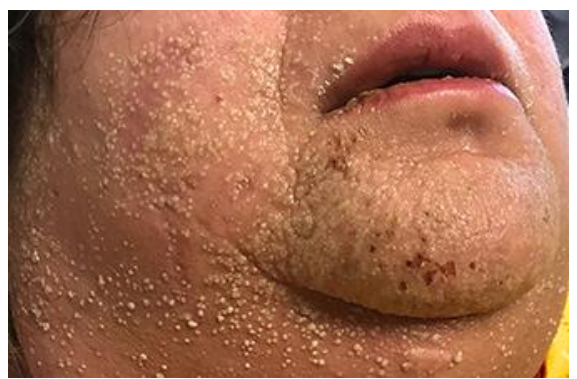

Fig. 1. Tiny pustules forming lakes of pus on the chin and cheeks.

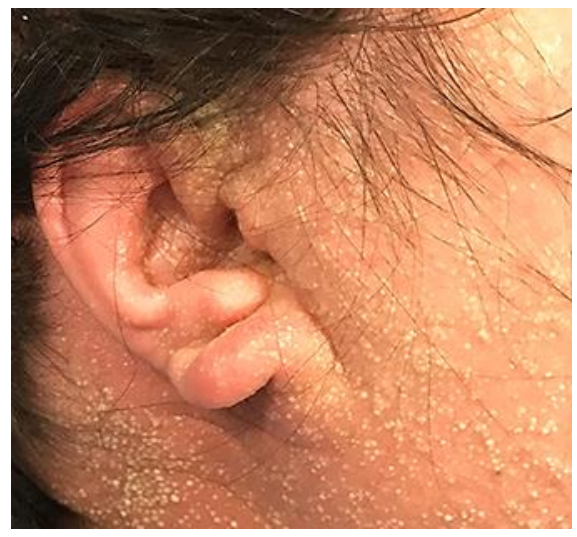

Fig. 2. Tiny pustules forming lakes of pus around her hairline. 
Case Reports
in Dermatology www.karger.com/cde

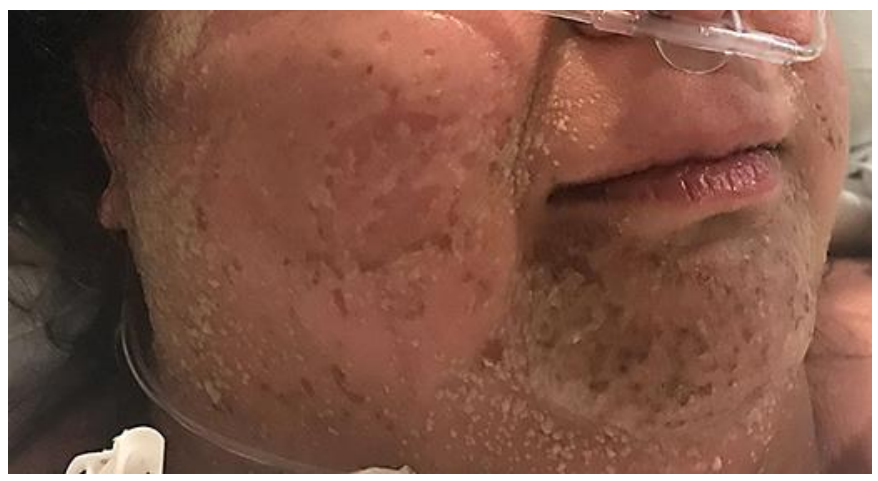

Fig. 3. Healing rash with desquamation.

Table 1. Investigations on admission and after recovery at discharge

\begin{tabular}{llll}
\hline & Reference range & Day 1 & On the day of discharge (day 9) \\
\hline Creatinine, mg/dL & $0.50-1.10$ & $4.18(\mathrm{H})$ & 0.69 \\
Total bilirubin, mg/dL & $0.3-1.2$ & 0.9 & 0.6 \\
AST, U/L & $14-34$ & $75(\mathrm{H})$ & 34 \\
ALT, U/L & $1-33$ & $64(\mathrm{H})$ & $64(\mathrm{H})$ \\
ALK PHOS, U/L & $42-98$ & 98 & $217(\mathrm{H})$ \\
\hline
\end{tabular}

H, high. 
Case Reports
in Dermatology

\begin{tabular}{l|l} 
Case Rep Dermatol 2021;13:47-53 \\
\hline DOI: 10.1159/000511369 & $\begin{array}{l}\text { (c) 2021 The Author(s). Published by S. Karger AG, Basel } \\
\text { www.karger.com/cde }\end{array}$ \\
\hline
\end{tabular}

Syed et al.: Acute Severe Generalized Exanthematous Pustulosis

Table 2. AGEP validation score by EuroSCAR study group - probable AGEP

\begin{tabular}{llc}
\hline Characteristic & Our patient's lesions & Score \\
\hline Pustules & Typical & 2 \\
Erythema & Compatible & 1 \\
Distribution/pattern & Typical & 2 \\
Postpustular desquamation & Yes & 1 \\
Mucosal involvement & No & 0 \\
Acute onset $(\leq 10$ days $)$ & Yes & -2 \\
Resolution $\leq 15$ days & Yes & 0 \\
Fever $\geq 38^{\circ} \mathrm{C}$ & Yes & 1 \\
PMN $\geq 7,000 / \mathrm{mm}^{3}$ & Yes & 1 \\
Histology & No histology & 0 \\
\hline Total score & & 6 \\
\hline
\end{tabular}

Score $\geq 8$ : definite; score 5-7: probable; score 1-4: possible; score 0: doubtful. PMN, polymorphonuclear neutrophils.

Table 3. Acute generalized exanthematous pustulosis (AGEP) vs. toxic epidermal necrolysis (TEN)

\begin{tabular}{lll}
\hline Lesion & AGEP & TEN \\
\hline Mucosal involvement & $\begin{array}{l}\text { Erythematous plaques, papules and } \\
\text { pustules }\end{array}$ & $\begin{array}{l}\text { Dusky papules/plaque associate with } \\
\text { sloughing }\end{array}$ \\
\hline Prognosis & Rare & Yes \\
\hline $\begin{array}{l}\text { Histopathological } \\
\text { examination }\end{array}$ & Good & Poor \\
\hline Treatment & Subcorneal neutrophilic pustules & Full-thickness epidermal necrosis with \\
& bulla \\
\hline
\end{tabular}

